\title{
Trends in tap and bottled water consumption among children and adults in the United States: analyses of NHANES 2011-16 data
}

\author{
Florent Vieux ${ }^{1}$, Matthieu Maillot ${ }^{1}$, Colin D. Rehm², Pamela Barrios ${ }^{3}$ and Adam Drewnowski ${ }^{4^{*}}$
}

\begin{abstract}
Background: Dietary Guidelines for Americans 2015-20 recommend choosing water in place of sugar-sweetened beverages (SSB). This study examined water consumption patterns and trends among children and adults in the US.

Methods: Dietary intake data for 7453 children (4-18y) and 15,263 adults (>19y) came from two $24 \mathrm{~h}$ dietary recalls in three cycles of the National Health and Nutrition Examination Survey (NHANES 2011-2016). Water was categorized as tap or bottled (plain). Other beverages were assigned to 15 categories. Water and other beverage intakes (in $\mathrm{mL} / \mathrm{d}$ ) were analyzed by sociodemographic variables and sourcing location. Consumption time trends from 2011 to 2016 were also examined. Total water intakes from water, other beverages and moisture from foods $(\mathrm{mL} / \mathrm{d})$ were compared to Dietary Reference Intakes (DRI) for water.

Results: Total dietary water $(2718 \mathrm{~mL} / \mathrm{d})$ came from water $(1066 \mathrm{~mL} / \mathrm{d})$, other beverages $(1036 \mathrm{~mL} / \mathrm{d})$ and from food moisture $(618 \mathrm{~mL} / \mathrm{d})$. Whereas total water intakes remained stable, a significant decline in SSB from 2011 to 2016 was fully offset by an increase in the consumption of plain water. The main sources of water were tap at home $(288 \mathrm{~mL} / \mathrm{d})$, tap away from home $(301 \mathrm{~mL} / \mathrm{d})$, and bottled water from stores $(339 \mathrm{~mL} / \mathrm{d})$. Water and other beverage consumption patterns varied with age, incomes and race/ethnicity. Higher tap water consumption was associated with higher incomes, but bottled water was not. Non-Hispanic whites consumed most tap water $(781 \mathrm{~mL} / \mathrm{d})$ whereas Mexican Americans consumed most bottled water $(605 \mathrm{~mL} / \mathrm{d})$. Only about $40 \%$ of the NHANES sample on average followed US recommendations for adequate water intakes.

Conclusion: The present results suggest that while total water intakes among children and adults have stayed constant, drinking water, tap and bottled, has been replacing SSB in the US diet.
\end{abstract}

Keywords: Water tap, Water bottled, Sugar-sweetened beverages, NHANES 2011-2016, Beverages, Time trends

\section{Introduction}

The Dietary Guidelines for Americans 2015-2020 have encouraged consumers to choose beverages with no added sugars, such as water, in place of sugar-sweetened beverages (SSB) [1]. Dietary intake surveys in the US have pointed to a continuing decline in SSB consumption [2, $3]$, especially among children, teenagers, and young adults [3-6]. However, SSB consumption rates are still relatively

\footnotetext{
* Correspondence: adamdrew@uw.edu

${ }^{4}$ Center for Public Health Nutrition, University of Washington, Box 353410 , Seattle, WA 98195, USA

Full list of author information is available at the end of the article
}

high among racial/ethnic minorities and younger age groups and continue to be associated with higher obesity risk $[3,4,6]$.

Replacing SSB with plain drinking water has become central to health promotion strategies, including those led by US federal agencies [1]. The Healthy, Hunger-Free Kids Act of 2010 [7] requires schools participating in the National School Lunch Program [8] to make free water available to students during meal times. The federal standards also require schools in the School Breakfast Program to make drinking water available when breakfast is served in the cafeteria [9]. Schools are encouraged to 
ensure that water fountains are clean and properly maintained, provide access to water fountains, dispensers, and hydration stations throughout the school, and allow students to have water bottles in class or to go to the water fountain [10]. Drinking fountains in public spaces are also viewed as an opportunity for public health. Much of the federal emphasis has been on plain drinking water from the tap.

Compared to the extensive literature on SSB consumption [2], less is known about consumption patterns and trends for drinking water, tap and bottled, among US children and adults. Past studies [11] have estimated that $56 \%$ of plain drinking water in the US comes from the tap, whereas $44 \%$ is bottled. Industry sources suggest that sales of bottled water have increased since then and that the global market for bottled water has grown substantially [12]. Analyses of the most recent National Health and Nutrition Examination Survey (NHANES) data would provide insights into the current tap and bottled water consumption trends in the US $[11,13]$.

The present hypothesis was that the reported decline in SSB consumption may have been offset, in part or in full, by a compensatory increase in drinking water. Such a finding would provide insight into the effectiveness of public health policies in the US [1]. The position of the Centers for Disease Control is that adequate water intakes would help increase overall water consumption, maintain hydration status, and reduce added sugar content of the diet, if substituted for SSB [10]. When it comes to maintaining hydration, examining compliance with standards and norms expressed either as water intakes in $\mathrm{mL} / \mathrm{d}$ or as ratio on water intakes to calories $(\mathrm{kcal} / \mathrm{d})$ would be of additional interest. The question was whether any population subgroup was failing to maintain adequate water intakes, as specified by the Institute of Medicine (IOM).

The present analyses were based on the nationally representative NHANES 2011-2016 dietary intakes database for children (4-18y) and adults $(\geq 19 y)$ in the US, including the most recent 2015-2016 cycle [14]. The present goals were to examine consumption patterns for water and other beverages by socio-demographic variables, including education and incomes and to explore consumption trends between 2011 and 2016. The adequacy of total water intakes, as compared to the IOM recommendations was also examined.

\section{Methods}

\section{Dietary intake databases}

Consumption data for drinking water, beverages, and foods came from three cycles of the nationally representative NHANES, corresponding to years 2011-12, 20132014, and 2015-2016 [15]. The three NHANES cycles provided a nationally representative sample of 7453 children (aged 4-18y) and 15,263 adults (aged >19y).

The NHANES 24-h recall uses a multi-pass method, where respondents reported the types and amounts of all food and beverages consumed in the preceding 24-h from midnight to midnight [16]. The multi-pass method was conducted by a trained interviewer using a computerized interface [17]. Respondents first identified a quick list of foods and beverages consumed. The time and occasion for each food item was also obtained. A more detailed cycle then recorded the amounts consumed, followed by a final probe for any often-forgotten foods (beverages, condiments). Day one interviews were conducted by trained dietary interviewers in a mobile examination center. Day two interviews were conducted by telephone some days later [18].

For children 4-5y, dietary recall was completed entirely by a proxy respondent (i.e. parent or guardian with knowledge of the child's diet) [16]. Proxy assisted interviews were conducted with children 6-11 years of age. Children 12-19y were the primary source of dietary recall but could be assisted by an adult who had knowledge of their diet.

We used a combination of the one-day value and the two-day mean to make use of all available dietary data. About $90 \%$ of people had two recalls. This method included all NHANES participants, even those without a second recall. Water consumers were defined as those NHANES participants who were drinking water on day one, day two, or both.

\section{Participant characteristics}

NHANES participants were stratified by gender and age. The age group cut-points were: 4-8y, 9-13y, 14-18y, 19$30 \mathrm{y}, 31-50 \mathrm{y}, 51-70 \mathrm{y}$, and $>70 \mathrm{y}$. These age groups generally correspond to the age groups used by the IOM. Race/ethnicity was defined as: non-Hispanic white, nonHispanic black, Mexican American, other Hispanic, and other/mixed race. Family income-to-poverty ratio (IPR) is the ratio of family income to the federal poverty threshold; the cut-points for IPR were $<1,1-1.99,2-$ 3.49 , and $\geq 3.5$.

\section{Water intakes from water and other beverages}

Water and other beverages were classified into groups. Plain drinking water was split into tap and bottled. Other beverages were classified as follows: milk and milk beverages, milk substitutes (soy milk), citrus juices, noncitrus juices, diet soda, regular soda, ready-to-drink tea, ready-to-drink coffee, fruit drinks, sports drinks, energy drinks, hot tea/coffee, alcoholic beverage, enhanced water, and supplemental beverages. Common examples by beverage category are presented in Table 5 in Appendix. The present analyses were for water from water and 
other beverages only. For example, milk consumed with cereal (i.e. not as a beverage) was assigned to the foods category.

The NHANES 24-h recalls for each participant provided information on the amount in grams of each food and beverage consumed [14]. The present results were for $\mathrm{mL}$ of water content from water and selected beverages and not for the volume of the beverages themselves (which may not be 100\% water). Moisture from foods was calculated as well.

The USDA Food and Nutrient Database for Dietary Studies (FNDDS) was used to calculate the energy content of the diet based on caloric beverages and solid foods [19]. These data were used to calculate the ratios of water intakes $(\mathrm{mL} / \mathrm{d})$ to energy intakes $(\mathrm{kcal} / \mathrm{d})$ for each NHANES participant.

\section{Time trend analyses 2011-2016}

Time trend analyses examined mean daily water intakes $(\mathrm{mL} / \mathrm{d})$ from tap and bottled water and water intakes from different beverage categories. Percent reported consumers for tap and bottled water was calculated as well, separately for each NHANES cycle.

\section{Determination of adequate water intakes}

In conventional analyses, the mean of two 24-h recalls does not represent the habitual intakes of an individual. Failing to meet water or nutrient recommendations on a particular day may not accurately reflect the long-term status of the individual. For that reason, the National Cancer Institute $(\mathrm{NCI})$ method was used to characterize the usual intake of water from water, beverages and foods [20-22]. This method has been used in other studies to estimate the usual intake of nutrients and food groups, including the population distribution of intakes.

\section{Sourcing location for water and other beverages}

The following NHANES sourcing options for foods and other beverages were selected: store, work/school, someone else (e.g. friends' home), quick-service restaurant (fast food), full-service restaurant, and other. Tap water does not have a source in NHANES; however, the source of water can be determined using information on the location of meals. For example, if a meal at a fast food restaurant was accompanied by tap water consumed at the same time, we can infer that the tap water was from "away from home". Tap water consumed at home was coded as "at home". For bottled water we created a variable called "home" or combined "store and home", as most home-consumed foods are from the store. Tap water category "outside of home" was reserved for occasions when tap water was consumed away from home and with no other foods at the same time.

\section{Data availability and ethical approval}

The necessary IRB approval for NHANES had been obtained by the National Center for Health Statistics (NCHS) [23]. Adult participants provided written informed consent. Parental/ guardian written informed consent was obtained for children. Children/adolescents $\geq 12 y$ provided additional written consent. All NHANES data are publicly available on the NCHS and USDA websites [14]. Per University of Washington (UW) policies, public data do not involve "human subjects" and their use requires neither IRB review nor an exempt determination. Such data may be used without any involvement of the Human Subjects Division or the UW Institutional Review Board.

\section{Statistical analyses}

The survey-weighted mean intakes of total water were evaluated overall and by age group, gender, race/ethnicity, and family income-to-poverty ratio. All analyses accounted for the complex survey design of NHANES and reflect dietary behaviors of the US adult population from 2011 to 16 .

Analyses of what proportion of NHANES 2011-2016 participants met the IOM recommendations for adequate hydration were based on habitual water intakes established using the National Cancer Institute method [24, 25]. The probability of water consumption was estimated to be 1 . Subsequent analyses specified the consumption-day amount using linear regression and intake data from 24-h recalls.

The consumption of tap and bottled water was evaluated separately for the entire population and for population subgroups. Survey-weighted means and corresponding standard errors were obtained. Hypothesis testing was based on a linear trend test which treats the NHANES cycles as a continuous variable. This trend test may be sensitive to extreme values in either the first (2011-12) or last (2015-2016) cycle and may not reflect weak non-linear trends. All analyses were conducted using SAS software, version 9.4 (SAS Institute Inc., Cary NC, USA) by using SURVEYREG, SURVEYMEANS and SURVEYFREQ procedures.

\section{Results}

\section{Total water intakes from water, other beverages, and} foods

Table 1 shows total water intakes in $\mathrm{mL} / \mathrm{d}$ by gender, age, socio-demographic groups, and eating occasion. Data are for total water intakes, water from water and other beverages, and moisture from foods. Total water intake was $2718 \mathrm{~mL} / \mathrm{d}$, of which $2100 \mathrm{~mL} / \mathrm{d}$ (77\%) came from water and other beverages and $618 \mathrm{~mL} / \mathrm{d}(23 \%)$ came from food moisture. Men had higher water intakes from all sources than did women $(2949 \mathrm{~mL}$ vs. $2495 \mathrm{~mL}$; $p<0.01)$. There was also a strong age effect. Total water intakes increased sharply with age, peaked for the 31$50 \mathrm{y}$ age group, and declined thereafter, dropping to $2355 \mathrm{~mL} / \mathrm{d}$ after the age of $70 \mathrm{y}$. 
Table 1 Water intakes $(\mathrm{mL} / \mathrm{d})$ from water, other beverages and foods (mean, standard error) by individual characteristics and meal occasion

\begin{tabular}{|c|c|c|c|}
\hline & Water, other beverages, and foods $(\mathrm{mL} / \mathrm{d})$ & Water and other beverages $(\mathrm{mL} / \mathrm{d})$ & Food moisture $(\mathrm{mL} / \mathrm{d})$ \\
\hline All $>4 y(N=22,716)$ & $2718(27)$ & $2100(26)$ & $618(6)$ \\
\hline \multicolumn{4}{|l|}{ Gender } \\
\hline Males $(N=11,206)$ & $2949(36)$ & $2285(34)$ & $664(6)$ \\
\hline Females $(N=11,510)$ & $2495(25)$ & $1921(24)$ & $574(7)$ \\
\hline$p$-value for effect & $<0.01$ & $<0.01$ & $<0.01$ \\
\hline \multicolumn{4}{|l|}{ Age } \\
\hline $4-8 y(N=2644)$ & $1441(18)$ & $938(16)$ & $503(8)$ \\
\hline $9-13 y(N=2501)$ & $1691(23)$ & $1143(20)$ & $547(8)$ \\
\hline $14-18 y(N=2308)$ & $2128(47)$ & $1609(44)$ & $518(8)$ \\
\hline $19-30 y(N=3248)$ & $2936(52)$ & $2331(48)$ & $606(10)$ \\
\hline $31-50 y(N=5071)$ & $3166(36)$ & $2513(35)$ & $652(9)$ \\
\hline $51-70 y(N=4873)$ & $2997(43)$ & $2339(42)$ & $658(7)$ \\
\hline$>70 y(N=2071)$ & $2355(28)$ & $1707(27)$ & $648(10)$ \\
\hline$p$-value for effect & $<0.01$ & $<0.01$ & $<0.01$ \\
\hline$p$-trend & $<0.01$ & $<0.01$ & $<0.01$ \\
\hline \multicolumn{4}{|l|}{ Race/ethnicity } \\
\hline non-Hispanic white $(N=7802)$ & $2879(31)$ & $2266(29)$ & $613(7)$ \\
\hline non-Hispanic black $(N=5365)$ & $2249(36)$ & $1695(32)$ & $554(7)$ \\
\hline Mexican American $(N=3698)$ & $2487(51)$ & $1857(48)$ & $630(10)$ \\
\hline Other Hispanic $(N=2473)$ & $2505(38)$ & $1897(34)$ & $609(8)$ \\
\hline Other/mixed race $(N=3378)$ & $2635(38)$ & $1899(38)$ & $737(13)$ \\
\hline$p$-value for effect & $<0.01$ & $<0.01$ & $<0.01$ \\
\hline \multicolumn{4}{|l|}{ IPR } \\
\hline$<1(N=5633)$ & $2461(49)$ & $1888(48)$ & $573(6)$ \\
\hline $1-1.99(N=5545)$ & $2579(38)$ & 1989 (36) & $590(8)$ \\
\hline $2-3.49(N=4209)$ & $2692(40)$ & $2092(39)$ & $601(9)$ \\
\hline$>3.49(N=5558)$ & $2952(38)$ & $2288(37)$ & $664(9)$ \\
\hline Missing $(N=1771)$ & $2616(56)$ & $1989(52)$ & $627(13)$ \\
\hline$p$-value for effect & $<0.01$ & $<0.01$ & $<0.01$ \\
\hline$p$-trend & $<0.01$ & $<0.01$ & $<0.01$ \\
\hline
\end{tabular}

Non-Hispanic whites had highest total water intakes $(2879 \mathrm{~mL} / \mathrm{d})$ and highest water intakes from water and other beverages $(2266 \mathrm{~mL} / \mathrm{d})$. Non-Hispanic blacks had lowest total water intakes $(2249 \mathrm{~mL} / \mathrm{d})$ and lowest water intakes from water and other beverages $(1695 \mathrm{~mL} / \mathrm{d})$. Total water intakes followed a socioeconomic gradient. Groups with higher IPR had the highest total water intakes $(2952 \mathrm{~mL} / \mathrm{d})$, had highest intakes of water and other beverages $(2288 \mathrm{~mL} / \mathrm{d})$ and derived most moisture from foods $(664 \mathrm{~mL} / \mathrm{d})$. The difference in total water intakes between IPR $<1(2461 \mathrm{~mL} / \mathrm{d})$ and IPR $>3.49$ was almost $500 \mathrm{~mL} /$ day. Adjusting for age, intakes were $2225 \mathrm{~mL} / \mathrm{d}$ in the lowest IPR and $2548 \mathrm{~mL} / \mathrm{d}$ in the highest IPR.

\section{Water intakes from water and other beverages}

Table 2 shows intakes of water, now separated into tap and bottled water, by individual socio-demographic variables and eating occasion. Total intake of drinking water, both tap and bottled, was $1066 \mathrm{~mL} / \mathrm{d}$. Tap water supplied $661 \mathrm{~mL} / \mathrm{d}$ whereas bottled water supplied $404 \mathrm{~mL} /$ d. Other beverages, caloric and non-caloric, supplied another $1034 \mathrm{~mL} / \mathrm{d}$. Thus, the daily distribution of dietary sources of water was tap water $(24 \%)$, bottled water (14\%), other beverages (38\%), and food moisture (23\%).

Men and women drank comparable amounts of tap and bottled water. There was a significant effect of age group. The consumption of tap and bottled water peaked at ages 31-50y and declined thereafter. People > 
Table 2 Water intakes $(\mathrm{mL} / \mathrm{d})$ from water and other beverages (mean, standard error) by socio-demographics and sourcing location

\begin{tabular}{|c|c|c|c|c|}
\hline & Water (tap+bottled) & Tap water & Bottled water & Other beverages \\
\hline All $>4 y \quad(N=22,716)$ & $1066(20)$ & $661(24)$ & $404(16)$ & $1034(17)$ \\
\hline \multicolumn{5}{|l|}{ Gender } \\
\hline Males $(N=11,206)$ & $1071(24)$ & $676(25)$ & $395(16)$ & $1214(24)$ \\
\hline Females $(N=11,510)$ & $1060(20)$ & $647(27)$ & $414(17)$ & $861(14)$ \\
\hline$p$-value for effect & 0.59 & 0.15 & 0.10 & $<0.01$ \\
\hline \multicolumn{5}{|l|}{ Age } \\
\hline $4-8 y(N=2644)$ & $430(15)$ & $264(18)$ & $165(12)$ & $508(11)$ \\
\hline $9-13 y(N=2501)$ & $577(19)$ & $359(21)$ & $218(18)$ & $567(12)$ \\
\hline $14-18 y(N=2308)$ & $866(34)$ & $481(34)$ & $385(21)$ & $743(24)$ \\
\hline $19-30 y(N=3248)$ & $1305(44)$ & $819(47)$ & $486(24)$ & $1026(21)$ \\
\hline $31-50 y(N=5071)$ & $1297(30)$ & $772(33)$ & $525(25)$ & $1217(28)$ \\
\hline $51-70 y(N=4873)$ & $1100(28)$ & $694(32)$ & $406(20)$ & $1239(22)$ \\
\hline$>70 y(N=2071)$ & $809(24)$ & $598(29)$ & $212(14)$ & $898(20)$ \\
\hline$p$-value for effect & $<0.01$ & $<0.01$ & $<0.01$ & $<0.01$ \\
\hline$p$-trend & $<0.01$ & $<0.01$ & $<0.01$ & $<0.01$ \\
\hline \multicolumn{5}{|l|}{ Race/ethnicity } \\
\hline non-Hispanic white $(N=7802)$ & $1109(26)$ & $781(27)$ & $328(16)$ & $1157(23)$ \\
\hline non-Hispanic black $(N=5365)$ & $894(29)$ & $359(23)$ & $534(23)$ & $802(14)$ \\
\hline MexicanAmerican $(N=3698)$ & $997(36)$ & $391(21)$ & $605(26)$ & $861(19)$ \\
\hline Other Hispanic $(N=2473)$ & $1041(33)$ & $497(41)$ & $544(34)$ & $856(18)$ \\
\hline Other/mixed race $(N=3378)$ & $1092(26)$ & $658(31)$ & $434(29)$ & $807(24)$ \\
\hline$p$-value for effect & $<0.01$ & $<0.01$ & $<0.01$ & $<0.01$ \\
\hline \multicolumn{5}{|l|}{ Income to poverty ratio (IPR) } \\
\hline$<1(N=5633)$ & $932(37)$ & $496(45)$ & $436(21)$ & $956(30)$ \\
\hline $1-1.99(N=5545)$ & $1003(27)$ & $555(27)$ & $448(22)$ & $986(27)$ \\
\hline $2-3.49(N=4209)$ & $1036(28)$ & $643(28)$ & $394(21)$ & $1055(25)$ \\
\hline$>3.49(N=5558)$ & $1181(29)$ & $821(32)$ & $360(20)$ & 1108 (19) \\
\hline Missing $(N=1771)$ & $1074(49)$ & $609(44)$ & $464(29)$ & $916(27)$ \\
\hline$p$-value for effect & $<0.01$ & $<0.01$ & $<0.01$ & $<0.01$ \\
\hline$p$-trend & $<0.01$ & $<0.01$ & $<0.01$ & $<0.01$ \\
\hline
\end{tabular}

70 y old drank less water than other groups; there was an age-related decline in bottled water $(212 \mathrm{~mL} / \mathrm{d})$ and other beverages $(898 \mathrm{~mL} / \mathrm{d})$.

Although the consumption of drinking water increased with rising IPR, the income effect operated in opposite directions for tap water and for bottled water. Higher IPR was associated with more tap water (from 495 to $821 \mathrm{~mL} / \mathrm{d}$ ) but, unexpectedly, with somewhat lower consumption of bottled water (from 436 to $360 \mathrm{~mL} / \mathrm{d}$ ).

There were also differences in consumption of drinking water by race/ethnicity. Non-Hispanic whites consumed the most tap water and the least bottled water $(781 \mathrm{~mL} / \mathrm{d}$ and $328 \mathrm{~mL} / \mathrm{d}$, respectively). Mexican Americans and non-Hispanic blacks consumed more bottled water than tap water, as did other Hispanics.
Men consumed more other beverages than did women ( $1214 \mathrm{~mL} / \mathrm{d}$ vs. $861 \mathrm{~mL} / \mathrm{d})$. Beverage consumption peaked at 51-70y and declined for $>70 y$ age group. Non-Hispanic whites drank the highest amounts of other beverages $(1157 \mathrm{~mL} / \mathrm{d})$; non-Hispanic blacks drank the least $(803$ $\mathrm{mL} / \mathrm{d})$. Water consumption from other beverages increased with IPR.

Separate analyses of caloric SSB, estimated water consumption from SSB at $288 \mathrm{~mL} / \mathrm{d}$, with peak consumption observed among younger adults aged $19-30 \mathrm{y}(410 \mathrm{~mL} / \mathrm{d})$. Non-Hispanic blacks consumed the most water from SSB $(368 \mathrm{~mL} / \mathrm{d})$; the other/mixed race group consumed the least $(205 \mathrm{~mL} / \mathrm{d})$. Water from SSB was lower among higher income groups $(209 \mathrm{~mL} / \mathrm{d})$ as compared to 390 $\mathrm{mL} / \mathrm{d}$ among lowest income groups. 
Time trends in SSB and water consumption 2011-2016 Table 3 shows time trends for water intake from water and other beverages for each NHANES cycle (20112016) and separately for children (4-18y) and for adults (>19y). Total water intakes did not change during this time period, remaining at approximately $2100 \mathrm{~mL} / \mathrm{d}$. However, there was a significant decline in the consumption of other beverages (from $1097 \mathrm{~mL} / \mathrm{d}$ to 970 $\mathrm{mL} / \mathrm{d}$ ) that was especially pronounced for children (from $675 \mathrm{~mL} / \mathrm{d}$ to $522 \mathrm{~mL} / \mathrm{d}$ ) and was significant for both children and for adults. That reduction in intake was largely caused by reduced consumption of SSB, which was highly significant among both children and adults. Children also consumed less water from non-SSB beverages. Analyses for trends were significant.

While total water intakes remained stable, the significant decline in SSB consumption was offset by a corresponding significant increase in the consumption of tap and bottled water. Among adults aged $>19 y$, the increase in tap and bottled water consumption from $1126 \mathrm{~mL} / \mathrm{d}$ to $1271 \mathrm{~mL} / \mathrm{d}$ was statistically significant. A smaller increase (from $577 \mathrm{~mL} / \mathrm{d}$ to $663 \mathrm{~mL} / \mathrm{d}$ ) among children aged 4-18y was not. The observed small increases in bottled water did not reach statistical significance.

Figure 1 shows time trends for water intakes from water and other beverages for each of the three NHANES cycles. Water has been separated into tap and bottled, whereas beverages are shown by category. The SSB category includes regular sodas, fruit drinks and ready to drink tea and coffee, and most sports and energy drinks. The data show that a progressive decline in beverages, including SSB has been compensated for by drinking water. Figure 1a (top) shows absolute amounts in $\mathrm{mL} / \mathrm{d}$, whereas Fig. 1b (bottom) shows the percent contribution of each water source to water intakes.

\section{Water intakes from water and other beverages by age}

Figure 2 summarizes water intakes from tap and bottled water and from different other beverage categories by age. The categories are listed in the figure key. Figure $2 \mathrm{a}$ (top) shows water intakes in $\mathrm{mL} / \mathrm{d}$, whereas Fig. $2 \mathrm{~b}$

Table 3 Time trends in water intakes $(\mathrm{mL})$ from tap, bottled water, and other beverages including SSV (mean, standard error)

\begin{tabular}{|c|c|c|c|c|c|}
\hline & \multicolumn{4}{|c|}{ NHANES cycle } & \multirow[t]{2}{*}{$p$-trend } \\
\hline & 2011-12 & 2013-14 & 2015-16 & $p$-value & \\
\hline \multicolumn{6}{|l|}{ All $>4 y$} \\
\hline Tap+Bottled water & $1011(33)$ & $1039(30)$ & $1144(38)$ & $<0.05$ & $<0.05$ \\
\hline Tap water & $643(32)$ & $639(48)$ & $700(43)$ & 0.51 & 0.29 \\
\hline Bottled water & $368(30)$ & $400(27)$ & $444(24)$ & 0.14 & 0.05 \\
\hline Other beverages & $1097(31)$ & $1038(32)$ & $970(21)$ & $<0.01$ & $<0.005$ \\
\hline SSB & $322(12)$ & $283(14)$ & $262(13)$ & $<0.01$ & $<0.005$ \\
\hline Not SSB & $775(32)$ & $755(31)$ & $708(21)$ & 0.17 & 0.09 \\
\hline Total & $2108(45)$ & 2077 (44) & $2114(46)$ & 0.82 & 0.92 \\
\hline \multicolumn{6}{|l|}{ Age 4-18y } \\
\hline Tap+Bottled water & $577(29)$ & $642(24)$ & $663(34)$ & 0.12 & 0.06 \\
\hline Tap water & $332(26)$ & $383(36)$ & $393(35)$ & 0.30 & 0.17 \\
\hline Bottled water & $245(31)$ & $259(18)$ & $269(23)$ & 0.82 & 0.53 \\
\hline Other beverages & $675(21)$ & $630(18)$ & $522(13)$ & $<.0001$ & $<0.0001$ \\
\hline SSB & $324(9)$ & $291(16)$ & $237(14)$ & $<.0001$ & $<0.0001$ \\
\hline Not SSB & $351(18)$ & $339(15)$ & $285(8)$ & $<0.001$ & $<0.005$ \\
\hline Total & $1253(38)$ & $1272(30)$ & $1185(30)$ & 0.11 & 0.16 \\
\hline \multicolumn{6}{|l|}{ Age $19 y+$} \\
\hline Tap+Bottled water & $1126(38)$ & $1143(36)$ & $1271(40)$ & $<0.05$ & $<0.05$ \\
\hline Tap water & 725 (38) & 706 (54) & $781(45)$ & 0.50 & 0.35 \\
\hline Bottled water & $400(31)$ & $437(30)$ & $490(28)$ & 0.11 & $<0.05$ \\
\hline Other beverages & 1208 (35) & 1144 (35) & $1088(27)$ & $<0.05$ & $<0.01$ \\
\hline SSB & $321(14)$ & $280(15)$ & $269(14)$ & $<0.05$ & $<0.05$ \\
\hline Not SSB & $887(37)$ & $864(34)$ & $819(25)$ & 0.27 & 0.13 \\
\hline Total & 2334 (49) & $2287(50)$ & $2359(51)$ & 0.60 & 0.73 \\
\hline
\end{tabular}




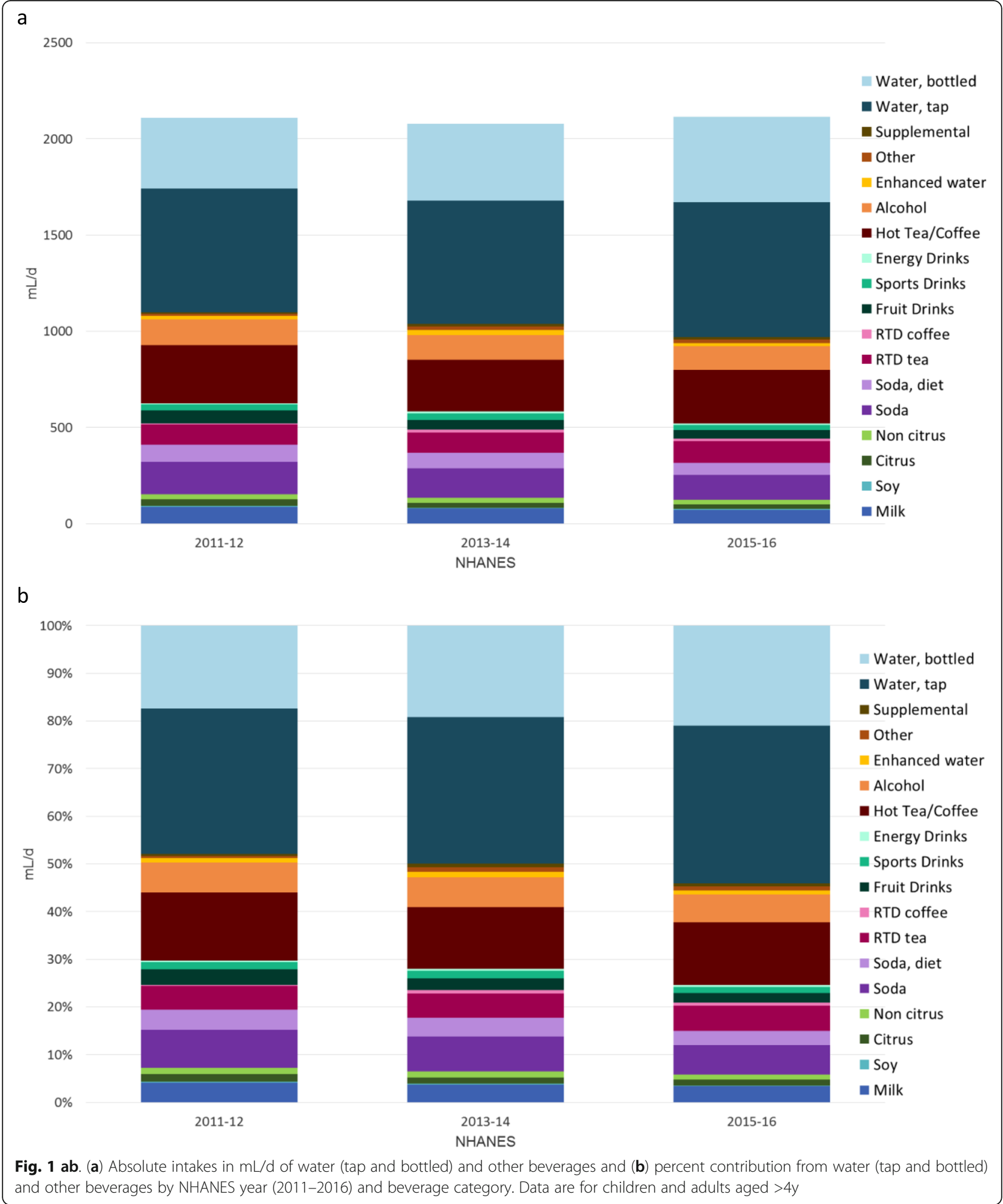




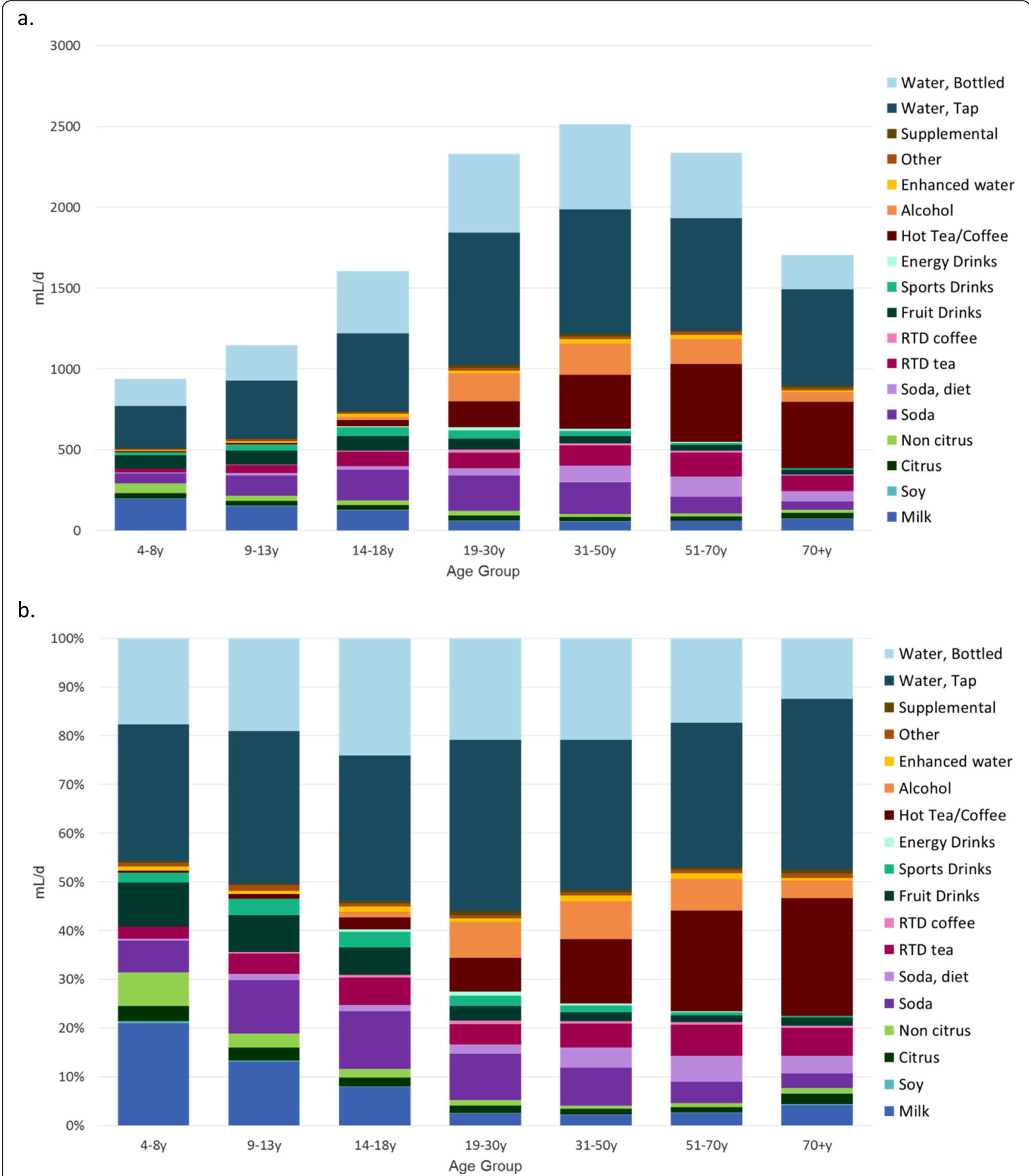

Fig. 2 ab. (a) Absolute intakes in $\mathrm{mL} / \mathrm{d}$ of water (tap and bottled) and other beverages and (b) percent contribution from water (tap and bottled) and other beverages by age group and beverage category 
(bottom) shows the percent contribution of different beverages to water intakes for each age group.

Water, tap and bottled, provided about $50 \%$ of water intakes, excluding moisture from food. Caloric and noncaloric beverages provided between $508 \mathrm{~mL} / \mathrm{d}$ and 1239 $\mathrm{mL} / \mathrm{d}$ of water depending on age. The type of beverages consumed varied as a function of age. Figure $2 \mathrm{a}$ shows that the consumption of milk was highest for the 4-8y age group and declined progressively with age. The consumption of $100 \%$ non-citrus juices (driven in large part by apple juice) and fruit drinks also declined with age. By contrast, the consumption of regular soda increased with age, peaked in early adult life (19-30y) and declined thereafter. The consumption of diet soda increased sharply after the age of $30 \mathrm{y}$. The consumption of $100 \%$ citrus juice did not show much variation with age.

The consumption of presweetened ready-to-drink (RTD) tea increased with age. The consumption of RTD coffee was low. Sports drinks and energy drinks were consumed primarily by adolescents and by young adults. The consumption of brewed coffee and tea increased sharply after the age of $18 \mathrm{y}$ and so did the consumption of alcohol. Older adults $(>70 \mathrm{y})$ were getting as much as $412 \mathrm{~mL} / \mathrm{d}$ of daily water (or $24 \%$ of water from beverages) from coffee and tea.

Figure $2 \mathrm{~b}$ shows clearly the age-related trends in water and beverage consumption. First, the consumption of milk, 100\% fruit juice, and juice drinks declined with age, whereas the consumption of SSB and water increased. The 19-30y age group derived most water from tap and bottled water but also from SSB. However, both tap and bottled water consumption declined with age, replaced by tea and coffee and, to a lesser extent, by alcohol.

These age-related trends were compounded by socioeconomic status. Figure 3 shows that the amounts and types of beverages consumed varied with IPR. Figure $3 \mathrm{a}$ (top) shows water intakes in $\mathrm{mL} / \mathrm{d}$, whereas Fig. 3b (bottom) shows the percent contribution of different beverages to water intakes for each IPR group. There was a small IPR linked decline in the consumption of milk and citrus and non-citrus juices. There was a sharp drop in the consumption of SSB that was partly offset by higher consumption of diet soda. The proportion of water from fruit drinks, sports drinks, and energy drinks declined. By contrast higher IPR was associated with higher percent contributions from brewed coffee and tea, enhanced water, and alcohol.

\section{Source locations of water and other beverages}

Most bottled water and other beverages $(1076 \mathrm{~mL} / \mathrm{d}$ or $75 \%$ of total) came from the store. Of this, $339 \mathrm{~mL} / \mathrm{d}$ came from store-bought bottled water and $737 \mathrm{~mL} / \mathrm{d}$ came from store bought other beverages. Figure 4 shows the distribution of store bought other beverages by category. Smaller amounts of other beverages and virtually no bottled water were obtained from restaurants (fullservice [FSR] and quick-service [QSR]), work/school or someone else.

Tap water consumption $(589 \mathrm{~mL} / \mathrm{d})$ was almost evenly split between tap water at home $(288 \mathrm{~mL} / \mathrm{d})$ and tap water away from home $(301 \mathrm{~mL} / \mathrm{d})$; as previously noted, it was not possible to differentiate tap water more finely due to the manner of data collection.

\section{Meeting recommendations for adequate water intakes}

These data analyses used the NCI method to establish habitual water intakes based on two $24 \mathrm{~h}$ recalls, following published procedures [25]. Based on the NCI method, only about $40 \%$ of the NHANES 2011-2016 sample met the IOM recommendations for adequate water intakes. Figure 5 shows the percent of participants within each age group that met IOM recommendations for adequate water intakes using the NCI method. Data for years 2011-2016 were pooled as there was little year-to-year variation. The data show that men aged $>70 y$ were least likely to meet the IOM recommendations; only $5.15 \%$ did so.

Table 4 shows that the observed water volume per $1000 \mathrm{kcal}$ for most groups was between $1.4-1.6 \mathrm{~L} / 1000$ $\mathrm{kcal}$, consistent with the desirable values $(\geq 1.0 \mathrm{~L} / 1000$ $\mathrm{kcal}$ ) as recommended by the IOM and by the European Food Safety Authority [24-26]. The only two age groups with values $<1.0 \mathrm{~L} / 1000 \mathrm{kcal}$ were children aged $4-13 \mathrm{y}$. Higher water volume per $100 \mathrm{kcal}$ was observed for nonHispanic Whites and for groups with higher IPR. NonHispanic Black participants and lower IPR groups had lowest water volumes per $1000 \mathrm{kcal}$.

\section{Discussion}

The present analyses, based on the most recent 20152016 NHANES data confirm that the consumption of SSB in the US continues to drop [1, 6, 27, 28]. While SSB may not be the biggest source of dietary energy for anyone except teenagers, they are the main source of added sugars in the American diet [29]. The Dietary Guidelines for Americans 2015-20, along with a number of industry-led initiatives specifically called for making water the beverage of choice $[1,30]$. Replacing caloric SSB with plain drinking water has become a priority area for interventions in school and public health nutrition [6]. Sales of bottled water in the US are also reported to be on the rise [31].

The present analyses provide several new insights into water and other beverage consumption patterns and trends. First, total dietary water intakes from drinking water, other beverages, and foods have remained stable from 2011 to 2016. Total amounts of water and other 


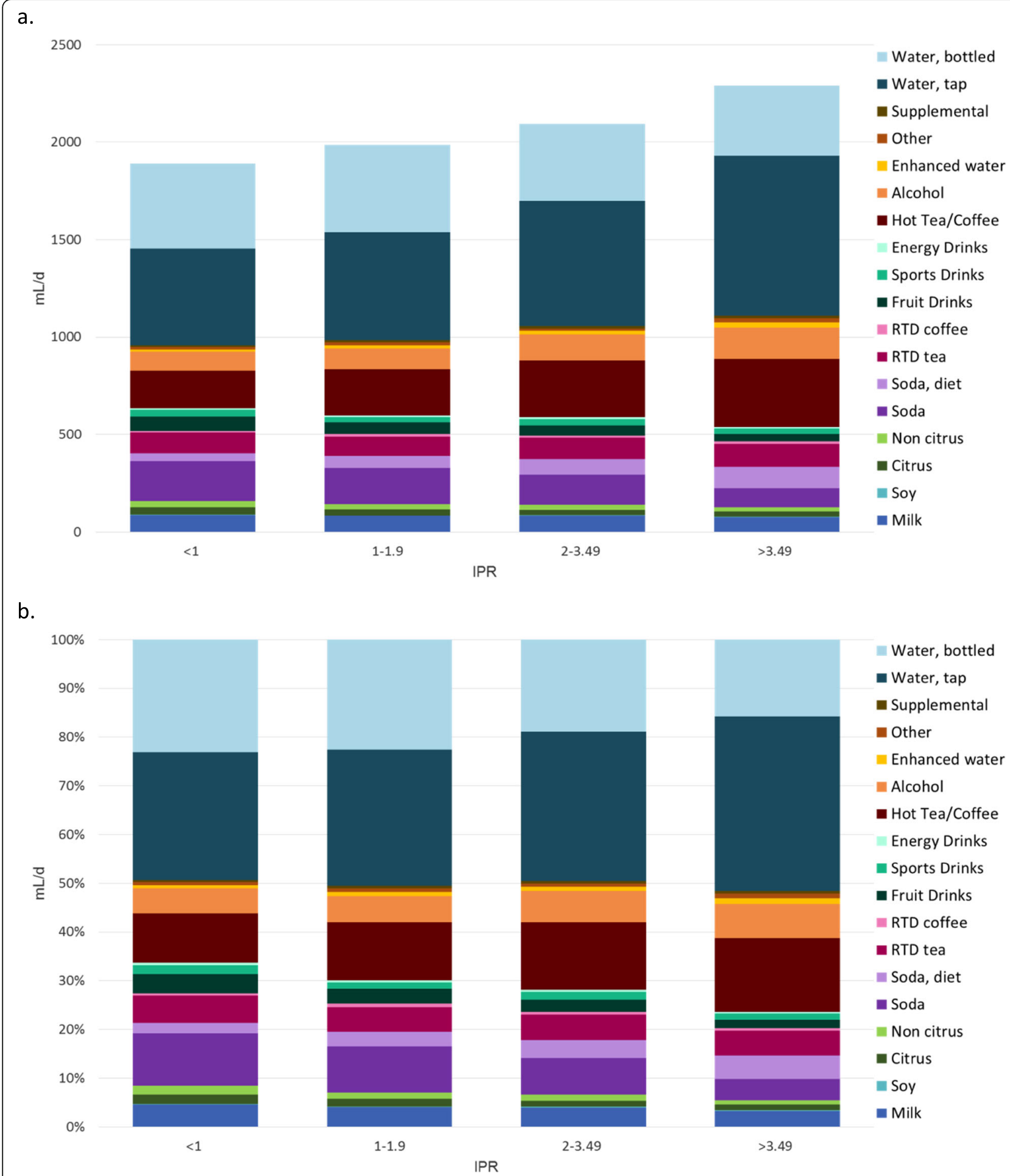

Fig. 3 ab. (a) Absolute intakes in $\mathrm{mL} / \mathrm{d}$ of water (tap and bottled) and other beverages and (b) percent contribution from water (tap and bottled) and other beverages by IPR and beverage category 


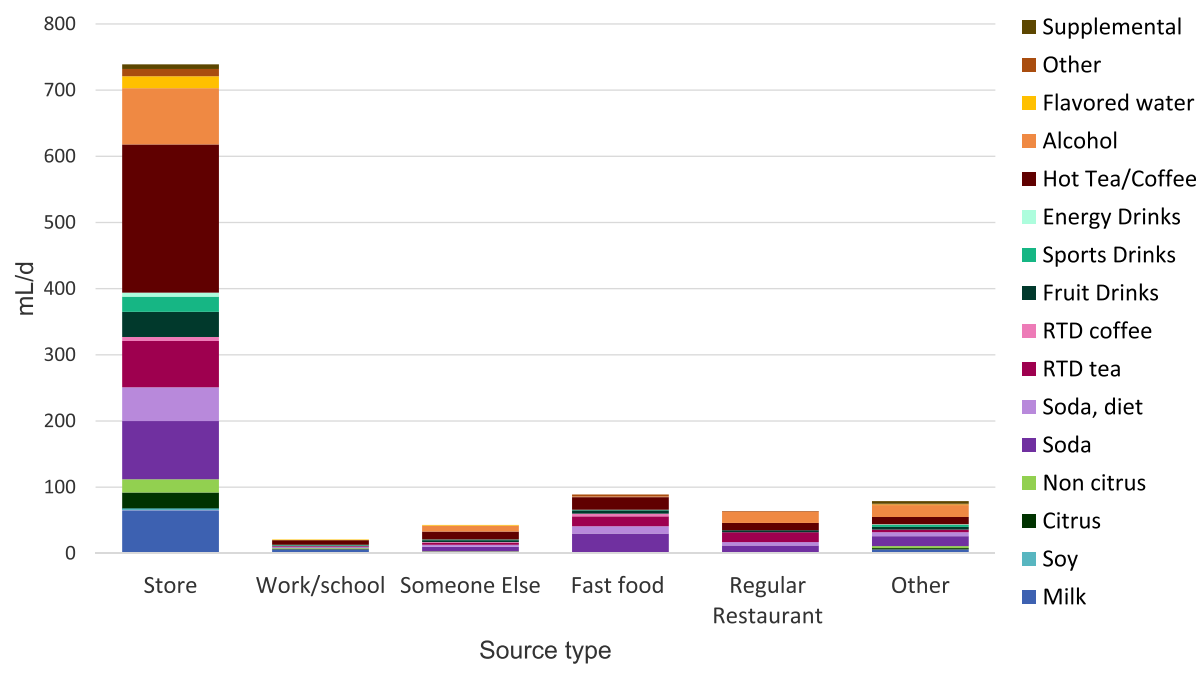

Fig. 4 Percentage of participants meeting IOM adequate intake recommendations for water by age group

beverages have also remained constant. We now show for the first time that the observed significant drop in SSB consumption has been offset by an increased consumption of plain drinking water. On the average, about $62 \%$ of drinking water came from the tap, a major increase from 56\% observed in the 2005-2010 NHANES database [11].

Second, and contrary to expectations, tap water consumption was higher at higher incomes, whereas the consumption of bottled water was higher at lower incomes. Consistent with previous findings, non-Hispanic whites and higher income groups in the present study consumed the largest amounts of tap water [11]. By contrast, Mexican Americans drank the most bottled water and the least tap water. In previous analyses of NHANES data, water consumption, both bottled and tap, among adults was significantly associated with higher education and incomes. The present data showed that the income effect (IPR) now operated in opposite directions.

The continuing positive social gradient in tap water consumption is a cause for concern. Whereas bottled water is purified or filtered, packaged, sealed, and distributed through retail channels, municipal tap water is delivered through pipes from reservoirs, rivers or aquifers. The quality of tap water has been variable and found to be problematic, especially in lower-income areas [32, 33]. There seems to be a growing perception, confirmed by research studies, that tap water is safe to drink only in affluent neighborhoods [32, 34]. The CDC does not advise tap water for anyone with a compromised immune system [35]. Additional studies have pointed to concerns with copper and lead [36]. Making

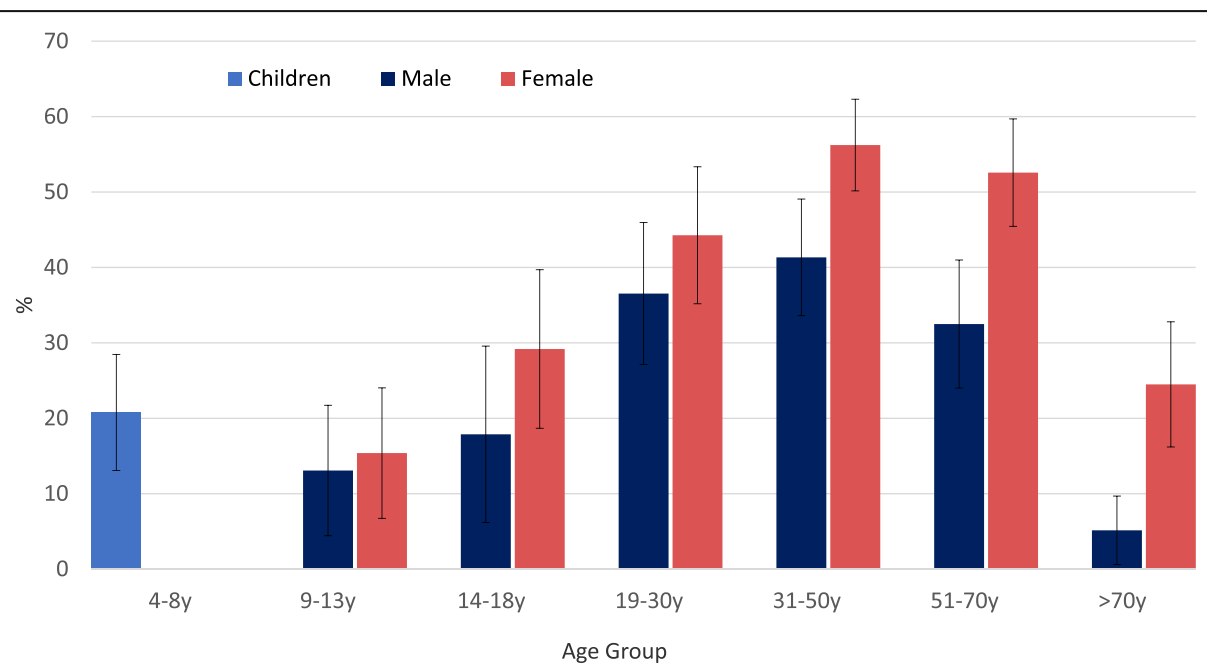

Fig. 5 Distribution of other beverages by sourcing location and beverage category. NHANES 2011-2016 
Table 4 Water density (mL/1000 kcal) by gender, age, race/ ethnicity, and IPR

\begin{tabular}{|c|c|}
\hline & Water density (mL/1000 kcal) \\
\hline \multicolumn{2}{|l|}{ All participants $>4 y(N=22,716)$} \\
\hline \multicolumn{2}{|l|}{ Gender } \\
\hline Males $(N=11,206)$ & $1333(14)$ \\
\hline Females $(N=11,510)$ & $1551(16)$ \\
\hline test & $<0.59$ \\
\hline \multicolumn{2}{|l|}{ Age } \\
\hline $4-8 y(N=2644)$ & $854(9)$ \\
\hline $9-13 y(N=2501)$ & $916(12)$ \\
\hline $14-18 y(N=2308)$ & $1151(27)$ \\
\hline $19-30 y(N=3248)$ & $1457(27)$ \\
\hline $31-50 y(N=5071)$ & $1609(20)$ \\
\hline $51-70 y(N=4873)$ & $1640(23)$ \\
\hline$>70 y(N=2071)$ & $1445(21)$ \\
\hline test & $<0.01$ \\
\hline \multicolumn{2}{|l|}{ Race/ethnicity } \\
\hline non-Hispanic white $(N=7802)$ & $1517(16)$ \\
\hline non-Hispanic black $(N=5365)$ & $1239(27)$ \\
\hline Mexican American $(N=3698)$ & $1276(26)$ \\
\hline Other Hispanic ( $N=2473)$ & $1388(27)$ \\
\hline Other/mixed race $(N=3378)$ & $1445(20)$ \\
\hline test & $<0.01$ \\
\hline \multicolumn{2}{|l|}{ IPR (cutpoints TBD) } \\
\hline$<1(N=5633)$ & $1348(24)$ \\
\hline $1-1.99(N=5545)$ & $1398(21)$ \\
\hline $2-3.49(N=4209)$ & $1433(27)$ \\
\hline$>3.49(N=5558)$ & $1513(18)$ \\
\hline Missing $(N=1771)$ & $1497(40)$ \\
\hline test & $<0.01$ \\
\hline
\end{tabular}

water the beverage of choice needs to be sensitive to the quality of the local water supply and to community resources, wants, and needs.

The inverse social gradient in bottled water consumption seems to be unique to the US. Studies with children in the UK showed that bottled water consumption was associated with higher household socioeconomic status (SES) [37, 38]. A social gradient for bottled water was not observed in France [39]. A previous study based on French INCA data examined water and other beverage consumption patterns by breakfast, AM snack, lunch, PM snack, dinner, and evening snack [39]. Another study based on data from the UK used time intervals to determine temporal distribution of water and beverage intakes [37]. There is a need for more international comparisons on who drinks tap water as opposed to bottled water [40], with what meal, and at what time of day [11, 37, 39].

The present analyses further showed that the consumption of bottled water was strongly age dependent $[11,13]$. Highly consumed by teenagers and young adults, bottled water was replaced in later life by tea and coffee and to a lesser extent alcohol. Older adults $>70 \mathrm{y}$ drank relatively little bottled water.

Finally, bottled water came mostly from the store. Very little bottled water came from fast food or full-service restaurants, or from work or school. This may change as schools may begin to use bottled water due to safety concerns $[34,36,40]$. By contrast, tap water was evenly split between tap at home and tap away from home.

The present analyses based on the NCI method showed that the IOM recommendations for adequate water intakes (AI) were met by only $40 \%$ of the US population on average, with numbers varying from 5 to $50 \%$ depending on age. The IOM AI values are set at $1700 \mathrm{~mL} / \mathrm{d}$ for boys and girls in the 4-8y age group and $2.1 \mathrm{~L} / \mathrm{d}$ for girls and $2.4 \mathrm{~L} / \mathrm{d}$ for boys in the 9-13y age group [24]. For 14-18 year-olds, the AI values are $3.3 \mathrm{~L} /$ $\mathrm{d}$ for boys and $2.3 \mathrm{~L} / \mathrm{d}$ for girls. The IOM reference values for water intake among adults are $2.7 \mathrm{~L} / \mathrm{d}$ for women and $3.7 \mathrm{~L} / \mathrm{d}$ for men [24]. The IOM AI goals are derived from the median intake of the US population whereas the European Food Safety Authority (EFSA) recommends a daily total water intake (water from food and beverages) of $2.5 \mathrm{~L}$ for men and $2.0 \mathrm{~L}$ for women to maintain urinary osmolality of $500 \mathrm{mOsmol} / \mathrm{L}$.

In past analyses of NHANES 2005-2010 [11], younger adults exceeded or came close to satisfying the DRIs for water. The shortfall between IOM recommendations and reality has been reported as most acute for young children and for older adults [11, 13]. Older men and women failed to meet the Institute of Medicine (IOM) AI values, with a shortfall in daily water intakes of 1218 $\mathrm{mL}$ and $603 \mathrm{~mL}$ respectively. Eighty-three percent of women and $95 \%$ of men $\geq 71 y$ failed to meet the IOM AI values for water [11].

However, it must be noted that non-compliance with IOM guidelines does not indicate dehydration. The second criterion of adequate hydration, water volume in $\mathrm{mL}$ per $1000 \mathrm{kcal}$, did not fall short of desirable values. Whereas the standard IOM recommendation is at least $1.0 \mathrm{~L}$ per $1000 \mathrm{kcal}$, the observed values of $\sim 1,5 \mathrm{~L} / 1000$ kcal were well above this threshold [24]. In NHANES 2005-2010 also, average water volume per $1000 \mathrm{kcal}$ was $1.2-1.4 \mathrm{~L} / 1000 \mathrm{kcal}$ for most population sub-groups, higher than the suggested minimum levels of $1.0 \mathrm{~L} /$ $1.000 \mathrm{kcal}[11]$.

On the other hand, beverage consumption in the US has shown a steady decline. The decline has been most acute for SSB but has also been observed with milk and 


\section{Appendix}

Table $\mathbf{5}$ Common examples by beverage category

\begin{tabular}{|c|c|}
\hline $\begin{array}{l}\text { Beverage } \\
\text { category }\end{array}$ & Most commonly reported examples \\
\hline Water, tap & Tap water \\
\hline Water, bottled & Bottled water (still) \\
\hline $\begin{array}{l}\text { Milk and milk } \\
\text { beverages }\end{array}$ & Whole milk, 2\% milk, 1\% milk \\
\hline Milk substitutes & Soy milk, almond milk \\
\hline Citrus juices & $\begin{array}{l}\text { Orange juice (canned/bottled), orange juice } \\
\text { (w/calcium), orange juice (NFS }{ }^{a} \text { ) }\end{array}$ \\
\hline $\begin{array}{l}\text { Non-citrus } \\
\text { juices }\end{array}$ & $\begin{array}{l}\text { Apple juice, grape juice, pineapple juice, fruit juice } \\
\text { blend, fruit juice }\left(N F S^{a}\right)\end{array}$ \\
\hline Soda, regular & Sugar-sweetened beverages, carbonated \\
\hline Soda, diet & Sweetened beverages, carbonated \\
\hline $\begin{array}{l}\text { Ready to drink } \\
\text { (RTD) tea }\end{array}$ & pre-sweetened tea, tea NFS ${ }^{a}$ presweetened with sugar \\
\hline $\begin{array}{l}\text { Ready to drink } \\
\text { (RTD) coffee }\end{array}$ & $\begin{array}{l}\text { pre-sweetened coffee, coffee NFS } \\
\text { presweetened with sugar }\end{array}$ \\
\hline $\begin{array}{l}\text { Fruit drinks } \\
\text { (regular \& diet) }\end{array}$ & $\begin{array}{l}\text { Fruit juice drink, fruit flavored drink } \\
\text { (made from powder), fruit juice drink (w/vitamin C) }\end{array}$ \\
\hline $\begin{array}{l}\text { Sports drinks } \\
\text { (regular \& diet) }\end{array}$ & Gatorade, Powerade \\
\hline $\begin{array}{l}\text { Energy drinks } \\
\text { (regular \& diet) }\end{array}$ & Red Bull \\
\hline Coffee and tea & $\begin{array}{l}\text { Regular coffee (from ground), decaffeinated } \\
\text { coffee (from instant), unsweetened tea }\end{array}$ \\
\hline $\begin{array}{l}\text { Flavored \& } \\
\text { enhanced water }\end{array}$ & $\begin{array}{l}\text { Carbonated water (unsweetened), Glaceau water, } \\
\text { sweetened carbonated water (e.g., tonic) }\end{array}$ \\
\hline $\begin{array}{l}\text { Alcoholic } \\
\text { beverages }\end{array}$ & Beer, lite beer, red wine \\
\hline $\begin{array}{l}\text { Other } \\
\text { beverages }\end{array}$ & Meal replacement beverages \\
\hline
\end{tabular}

${ }^{\mathrm{a}}$ NFS Not further specified

$100 \%$ orange juice. While the replacement of SSB with plain water does have the benefit of removing added sugar, consistent with the Dietary Guidelines goals, the replacement of milk or $100 \%$ juice with water may not have the same nutritional benefits. Total water intake below IOM recommended levels may also be a cause for concern, especially among older adults.

The present analyses had limitations. First, the NHANES data are based on self-report and are subject to random and systematic reporting errors. In particular, a 24-h recall may systematically underestimate water and other beverage intake, especially outside of meals since it is very difficult for individuals to remember exactly how much tap water they had outside of meals. Fluid-specific records, used in smaller scale studies, may provide higher quality data. The use of proxy respondents for children ages 4-5y and proxy assisted interviews for children 6-11 make the collection of accurate data especially challenging. The 2 days of dietary recalls used different methods to collect the data, which may affect the estimates of water consumption. Underreporting of water intakes would lead to overestimating the percent of adults who fail to meet the recommended intakes. However, the NHANES has the advantage of being based on a large, nationally representative population sample. The NHANES dataset forms the basis for dietary surveillance in the US.

\section{Conclusion}

The SSB in the US diet are in the process of being replaced by plain water, both tap and bottled. This is an encouraging finding when it comes to public health goals. However, water consumption patterns showed wide variations by socioeconomic status, age group, and race/ethnicity. Social marketing strategies to promote water consumption, tap or bottled, will need to take these factors into account.

\section{Abbreviations \\ FNDDS: USDA Food and Nutrient Database for Dietary Studies; FSR: Full- service restaurant; IOM: Institute of Medicine; IPR: Income-to-Poverty Ratio; $\mathrm{NCl}$ : National Cancer Institute; NHANES: National Health and Nutrition Examination Survey; QSR: Quick-service restaurant; RTD: Ready-to-drink; SES: Socioeconomic status; SSB: Sugar-Sweetened Beverages}

\section{Acknowledgments \\ Not Applicable.}

\section{Authors' contributions}

All authors (FV, MM, CDR, PB, and AD) conceptualized study design, formulated analytical questions and contributed to the manuscript preparation. Colin Rehm created the dataset, while Florent Vieux and Matthieu Maillot performed the principal analyses. Adam Drewnowski acted as lead writer of the manuscript. All authors (FV, MM, CDR, PB and AD) reviewed and approved the manuscript

\section{Funding}

Analyses of publicly available federal NHANES databases were sponsored by PepsiCo Inc. and conducted by MS-Nutrition.

\section{Availability of data and materials}

Data used in the study is publicly available through the NHANES database (at https://wwwn.cdc.gov/nchs/nhanes/continuousnhanes/default.aspx).

\section{Ethics approval and consent to participate}

The necessary IRB approval for NHANES was obtained by the National Center for Health Statistics. All NHANES data are publicly available on the NCHS and USDA websites. Per University of Washington (UW) policies, public data do not involve "human subjects" and their use requires neither IRB review nor an exempt determination. Such data may be used without any involvement of the Human Subjects Division or the UW Institutional Review Board.

\section{Consent for publication}

All authors give consent for publication.

\section{Competing interests}

Florent Vieux and Matthieu Maillot are employees of MS- Nutrition. Pamela Barrios is employed by PepsiCo Inc. Adam Drewnowski has received contracts, consulting fees and honoraria from entities both public and private with an interest in beverage consumption, including SSB and bottled water manufacturers and distributors such as PepsiCo, Nestle, and Danone. Colin D. Rehm has no conflicts to report. The views expressed in this work are those of the authors and do not necessarily reflect the position or policy of Pepsico Inc.

\section{Author details}

${ }^{1}$ MS-Nutrition, 27 bld Jean Moulin Faculté de Médecine la Timone, Laboratoire C2VN, 13385 Marseille, cedex 5, France. ${ }^{2}$ Albert Einstein College 
of Medicine, Montefiore Medical Center, New York, NY 10467, USA. ${ }^{3}$ Pepsico Inc, Purchase, New York, NY 10577, USA. ${ }^{4}$ Center for Public Health Nutrition, University of Washington, Box 353410, Seattle, WA 98195, USA.

Received: 1 October 2019 Accepted: 13 January 2020

Published online: 29 January 2020

\section{References}

1. U.S. Department of Health and Human Services and U.S. Department of Agriculture. In: Dietary Guidelines for Americans 2015-2020. Washington; 2015. https://health.gov/dietaryguidelines/2015/guidelines/. Accessed 19 Nov 2019.

2. Bleich SN, Vercammen KA, Koma JW, Li Z. Trends in beverage consumption among children and adults, 2003-2014. Obesity. 2018;26:432-41.

3. Mesirow MSC, Welsh JA. Changing Beverage Consumption Patterns Have Resulted in Fewer Liquid Calories in the Diets of US Children: National Health and Nutrition Examination Survey 2001-2010. J Acad Nutr Diet. 2015; 115:559-566.e4.

4. Muckelbauer R, Gortmaker SL, Libuda L, Kersting M, Clausen K, Adelberger B, et al. Changes in water and sugar-containing beverage consumption and body weight outcomes in children. Br J Nutr. 2016;1 15:2057-66.

5. Rosinger A, Herrick K, Gahche J, Park S. Sugar-sweetened Beverage Consumption Among U.S. Youth, 2011-2014. Hyattsville. NCHS Data Brief, no. 271. 2017:1-7.

6. Vargas-Garcia EJ, Evans CEL, Prestwich A, Sykes-Muskett BJ, Hooson J, Cade JE. Interventions to reduce consumption of sugar-sweetened beverages or increase water intake: evidence from a systematic review and meta-analysis. Obes Rev. 2017:18:1350-63.

7. USDA Food and Nutrition Service. Healthy hunger-free kids act. 2013. https://www.fns.usda.gov/school-meals/healthy-hunger-free-kids-act. Accessed 19 Nov 2019

8. USDA Food and Nutrition Service. National School Lunch Program https:// www.fns.usda.gov/nslp. Accessed 19 Nov 2019

9. USDA Food and Nutrition Service. School Breakfast Program https://www. fns.usda.gov/sbp/school-breakfast-program. Accessed 19 Nov 2019.

10. Centers for Disease Control and Prevention. Water Access. $2019 \mathrm{https}: / \mathrm{www}$. cdc.gov/healthyschools/npao/wateraccess.htm/. Accessed 19 Nov 2019.

11. Drewnowski A, Rehm CD, Constant F. Water and beverage consumption among adults in the United States: cross-sectional study using data from NHANES 2005-2010. BMC Public Health. 2013;13:1068.

12. ReportBuyer. The global bottled water market size is expected to reach USD 215.12 billion by 2025. PR Newswire. 2018; https://www.prnewswire.com/ news-releases/the-global-bottled-water-market-size-is-expected-to-reachusd-215-12-billion-by-2025\%2D\%2D300702642.html. Accessed 19 Nov 2019.

13. Drewnowski A, Rehm CD, Constant F. Water and beverage consumption among children age 4-13y in the United States: Analyses of 2005-2010 NHANES data. Nutr J. 2013;12:1

14. Centers for Disease Control and Prevention. National Health and Nutrition Examination Survey Data. 2018. https://wwwn.cdc.gov/nchs/nhanes/ continuousnhanes/default.aspx. Accessed 19 Nov 2019.

15. Centers for Disease Control and Prevention. National Center for Health Statistics (NHANES) -- About the National Health and Nutrition Examination Survey: CDC; 2017. https://www.cdc.gov/nchs/nhanes/about_nhanes.htm Accessed on 19 Nov 2019

16. Centers for Disease Control and Prevention. National Health and Nutrition Examination Survey Questionnaire: Dietary Interview Component. 2011. https://www.cdc.gov/nchs/data/nhanes/nhanes_11_12/dietary_post_recall_ qs_2011.pdf. Accessed 19 Nov 2019

17. Centers for Disease Control and Prevention. MEC In-Person Dietary Interviewers Procedures Manual. 2002. https:/www.cdc.gov/nchs/data/ nhanes/nhanes_03_04/DIETARY_MEC.pdf. Accessed 19 Nov 2019.

18. Centers for Disease Control and Prevention. National Health and Nutrition Examination Survey Questionnaire: Phone Follow-Up Dietary Interviewer Procedures Manual. 2010. https://wwwn.cdc.gov/nchs/data/nhanes/2009-2 010/manuals/phone_follow_up_dietary_procedures_manual_mar_2010.pdf. Accessed 19 Nov 2019.

19. Agricultural Research Service. USDA National Nutrient Database for Standard Reference. Nutr Data Lab. 2018; https://fdc.nal.usda.gov/. Accessed 19 Nov 2019.
20. Centers for Disease Control and Prevention. Advanced Dietary Analyses. 2011. https://www.cdc.gov/nchs/tutorials/dietary/advanced/. Accessed 19 Nov 2019.

21. Jéquier $\mathrm{E}$, Constant $\mathrm{F}$. Water as an essential nutrient: the physiological basis of hydration. Eur J Clin Nutr. 2010;64:115-23.

22. Kenefick RW, Cheuvront SN. Hydration for recreational sport and physical activity. Nutr Rev. 2012;70:S137-42.

23. Centers for Disease Control and Prevention. NHANES - NCHS Research Ethics Review Board Approval. 2017. https:/www.cdc.gov/nchs/nhanes/ irba98.htm\%0D. Accessed 19 Nov 2019.

24. Institute of Medicine. Dietary Reference Intakes for Water, Potassium, Sodium, Chloride, and Sulfate. Washington. https://www.nal.usda.gov/sites/ default/files/fnic_uploads/water_full_report.pdf

25. National Cancer Institute. Usual Dietary Intakes: The NCI Method. 2018. https:// epi.grants.cancer.gov/diet/usualintakes/method.html. Accessed 19 Nov 2019.

26. European Food Safety Authority. Scientific opinion on dietary reference values for water. EFSA J. 2010;8:1459.

27. Vercammen KA, Frelier JM, Lowery CM, McGlone ME, Ebbeling CB, Bleich SN. A systematic review of strategies to reduce sugar-sweetened beverage consumption among 0-year to 5-year olds. Obes Rev. 2018;19:1504-24.

28. Ford CN, Ng SW, Popkin BM. Ten-year beverage intake trends among US preschool children: rapid declines between 2003 and 2010 but stagnancy in recent years. Pediatr Obes. 2016;11:47-53.

29. Drewnowski A, Rehm CD. Consumption of added sugars among US children and adults by food purchase location and food source. Am J Clin Nutr. 2014:100:901-7.

30. Drewnowski A, Caballero B, Das JK, French J, Prentice AM, Fries LR, et al. Novel public-private partnerships to address the double burden of malnutrition. Nutr Rev. 2018;76:805-21.

31. Rosinger AY, Herrick KA, Wutich AY, Yoder JS, Ogden CL. Disparities in plain, tap and bottled water consumption among US adults: National Health and nutrition examination survey (NHANES) 2007-2014. Public Health Nutr. 2018; 21:1455-64.

32. Brooks CJ, Gortmaker SL, Long MW, Cradock AL, Kenney EL. Racial/ethnic and socioeconomic disparities in hydration status among US adults and the role of tap water and other beverage intake. Am J Public Health. 2017;107: 1387-94.

33. Gostin LO. Politics and public health: the Flint drinking water crisis. Hast Cent Rep. 2016:46:5-6.

34. Onufrak SJ, Park S, Sharkey JR, Merlo C, Dean WR, Sherry B. Perceptions of tap water and school water fountains and association with intake of plain water and sugar-sweetened beverages. J Sch Health. 2014;84:195-204.

35. Dykewicz C, Jaffe H, Kaplan J. Guidelines for preventing opportunistic infections among hematopoietic stem cell transplant recipients; recommendations of $C D C$, the infectious disease Society of America and the American Society of Blood and Marrow Transplantation. MMWR Recomm Reports. 2000;49:1-128.

36. Fox M. Lead in water: study shows many schools have far too much. NBC News. 2019; https://www.nbcnews.com/health/health-news/lead-water-studyshows-many-schools-have-far-too-much-n956851. Accessed 19 Nov 2019.

37. Vieux F, Maillot M, Constant F, Drewnowski A. Water and beverage consumption patterns among 4 to 13-year-old children in the United Kingdom. BMC Public Health BMC Public Health. 2017;17:1-12.

38. Guelinckx I, Tavoularis G, König J, Morin C, Gharbi H, Gandy J. Contribution of water from Food and fluids to Total water intake: analysis of a French and UK population surveys. Nutrients. 2016;8:630.

39. Vieux F, Maillot M, Constant F, Drewnowski A. Water and beverage consumption among children aged 4-13 years in France: analyses of INCA 2 (Étude Individuelle Nationale des Consommations Alimentaires 2006-2007) data. Public Health Nutr. 2016;19:2305-14.

40. Patel Al, Shapiro DJ, Wang YC, Cabana MD. Sociodemographic characteristics and beverage intake of children who drink tap water. Am J Prev Med. 2013;45:75-82.

\section{Publisher's Note}

Springer Nature remains neutral with regard to jurisdictional claims in published maps and institutional affiliations. 